\title{
Competing Cybermediaries
}

\author{
Bernard Caillaud $^{1}$ and Bruno Jullien ${ }^{2}$
}

September 2000

${ }^{1}$ CERAS-ENPC (URA 2036, CNRS), Paris and CEPR, London; email: caillaud@enpc.fr.

${ }^{2}$ GREMAQ (UMR 5604, CNRS) and IDEI, Toulouse, France; email: bjullien@cict.fr 


\begin{abstract}
A bstract
We examine a price competition game between two intermediaries offering to match two sides of a market on the Internet. Competition is characterized by asymmetric network externalities. We account for some specificities of cybermediation, in particular access vs usage pricing and the possibility of using the services of several intermediaries. When only registration fees are used and agents register with at most one cybermediary, there exists an equilibrium where one firm corners the market with positive profits. Introducing either fees that are contingent on successful matching or the possibility of registration with two cybermediaries cancels the profit for equilibria where only one cybermediary receives all the demand. Other types of equilibria are discussed.
\end{abstract}




\section{Introduction}

While the Internet has already stimulated a great deal of work on issues related to the infrastructure and access (see Varian and Shapiro (1998) for a general presentation of the economics of the Internet), very little is known so far on the issues related to the content of the services proposed on the World Wide Web. Following a study by The University of Austin (internetindicators.com), the activities related to Internet can be decomposed into four main categories: infrastructures, support applications and services, intermediation, sales of good and services on line. The study estimates that intermediation already accounts for nearly $20 \%$ of the total revenue generated by these activities ( $\$ 524$ milliards), of the order of the share of business-tobusiness (B2B) e-commerce, and far more than business-to-consumers (B2C) e-commerce. These figures show that intermediation represents a significant part of the activity.

The on-going process at work for electronic commerce is often describe as a process of de-intermediation and re-intermediation which refers to the fact that the intermediation process eliminates some traditional intermediaries (as for example banks and brokers in finance) and new forms of intermediation appear that were not conceivable before (see the survey on e-commerce in The Economist). The main role of intermediaries is to gather and process information on users that visit their website so as to help different classes of agents, in particular buyers and sellers of one specific good, to find each others. Although intermediaries may also provide services to facilitate transactions, a specificity of many of them is that they specialize on the pure informational aspects of intermediation, the physical part being left to sellers' distribution system. This article is concerned with this new type of specialized intermediaries, often referred to as cybermediaries. Pure informational intermediation is for example proposed by providers of on-line dating services that help users find a "romantic partner" (e.g. match.com); search engines also provide informational intermediation by finding websites that propose services for the specific need or inquiry on users; auction sites or aggregators of supply and demand organize on-line markets where information about needs and offers is critical. ${ }^{1}$ Even e-commerce firms (e.g. Amazon.com) perform informational intermediation between readers and books.

The aspect that we want to emphasize here is that the nature of the intermediation activity is a source of network externalities. Typically the value of an intermediary for a buyer relates to the number of goods and sellers that can be reached through this intermediary, as the value for a seller depends

\footnotetext{
${ }^{1}$ See the survey on e-commerce in The Economist and Kaplan and Sawhney (2000).
} 
on the size of the demand it will face with it. The activity thus involves asymmetric network effects; one type of users is interested in the number of users of another type. Moreover, different types of users buy different services and they face different types of prices. The combination of these two factors, asymmetric network externality and third degree price discrimination, opens the possibility of cross-subsidization among users. Indeed, an intermediary may subsidy the participation of some agents in order to increase its attractiveness for other participants. The possibility of cross-subsidization affects drastically the outcome of competition compared to the more standard situations with competition and network externalities (as developed by Katz-Shapiro $(1985,1994)$ and Farrell-Saloner $(1985)){ }^{2}$ This article is a first attempt to understand some of the consequences of these factors on the competition between cybermediaries. ${ }^{3}$ In doing so we will account for some specificities of cybermediation, and in particular the pricing schemes and the possibility of multiple registration.

\section{A model of intermediation}

Consider two classes of economic agents, labelled $i=1$ and 2. Each class consists in a continuum of agents of mass 1 . These classes of agents could represent buyers and sellers, up-stream suppliers and downstream users, electronic shopping malls and standard consumers,... Each agent on side $i$ of the market is interested in trading with one specific agent, and only one, on the other side $j$ of the market for some specific good or service; hence perfect matching yields utility $u_{\mathrm{i}}$ for type $i$ agent, while the absence of matching yields zero utility to agents. For later use, we will rank agents so that $u_{1}<u_{2}$. The good offered or demanded by an agent is perfectly observable by an agent of the other population once they meet, but ex ante there is no chance that a particular $i$-agent finds its perfect match within the set of infinitely many $j$-agents.

There exists an electronic technology that allows to process, select and use information on a population of agents. A firm with this technology acts as a "cybermediary". A cybermediary helps agents find their perfect

\footnotetext{
${ }^{2}$ In a sense the problem can be seen as a problem of network competition with price discrimination. Our work is thus related to the work of Innes-Sexton (1997) which shows how a monopoly may price-discriminate between similar consumers to prevent the formation of consumers' coalitions.

${ }^{3}$ Yanelle (1996) studies Bertrand competition between intermediaries. A key difference is that in her model intermediaries buy and resale while in ours they only match buyers and sellers. The issue of network effect that emerges in our context translates into the potential rationing of demand in her model.
} 
match within its population of registered agents, provided the matching agent belongs has indeed registered. For simplicity, we assume that registration and connection costs are negligeable. Given that agents are perfectly identical except with respect to the specific good they are interested in, their decision to register or to connect to a given cybermediary are independent of the good they want to trade. Therefore, if in equilibrium $n_{i}^{k}$ agents of type $i$ are registered or connect to a cybermediary $k$, these $n_{\mathrm{i}}^{\mathrm{k}}$ agents are drawn randomly among all $i$-agents and an agent of type $j$ has probability $n_{\mathrm{i}}^{\mathrm{k}} \in[0,1]$ to find its $i$-match through this cybermediary $k$. This agent of type $j$ has therefore expected utility $n_{\mathrm{i}}^{\mathrm{k}}\left(u_{\mathrm{j}}-t_{\mathrm{j}}^{\mathrm{k}}\right)-p_{\mathrm{j}}^{\mathrm{k}}$ of connecting to cybermediary $k$ if a price $p_{j}^{\mathrm{k}}$ is charged as an up-front connection/registration fee for $j$-agents and a price $t_{j}^{k}$ is charged on realized transaction through intermediary $k{ }^{4}$ The ability of charging a fee per match depends on the ability to monitor the transactions, so that we will contrast the case where this is not possible and the case where it is possible. Moreover we impose that $u_{j} \geq t_{j}^{k} \geq 0$ because a negative fee would induce false matching to collect the fee. On the other hand the price $p_{\mathrm{j}}$ can be negative. A negative price can be interpreted as a the consequence of gifts given to joining members, or as the result of the addition of free services to the basic matching service.

When an agent can register with many cybermediaries as in section 4.3, the same probabilistic interpretation applies. Let $n_{\mathrm{i}}^{\mathrm{k}}$ denote the proportion of $i$-users that register with $k$ and possibly with other intermediaries, and $n_{\mathrm{i}}^{\mathrm{k}, \mathrm{l}}$ the proportion of $i$-users that register with intermediaries $k, l$ and possibly others, a type- $j$ agent who only registers with intermediary $k$ has probability $n_{\mathrm{i}}^{\mathrm{k}}$ to find its $i$-match, while an agent of type- $j$ who simultaneously registers to both intermediaries $k$ and $l$ has total probability $n_{\mathrm{i}}^{\mathrm{k}}+n_{\mathrm{i}}^{l}-n_{\mathrm{i}}^{\mathrm{k}, \mathrm{l}}$ to find its match at one of the two intermediaries. In particular, if all type- $j$ agents register with some intermediary in equilibrium, a $i$-agent who registers with all active cybermediaries will find a match for sure. It is useful to interpret this modelling option as a multihoming strategy, which increases the probability of reaching consumers interested in the goods or services offered by making the firm known to users that visit at least one of many intermediaries' websites.

\section{A monopolist cybermediary}

As a benchmark, consider the case of a monopolist cybermediary. The general form of the pricing strategy we assume consists in access or registration fees,

\footnotetext{
${ }^{4}$ Note that we assume that transaction fees do not affect the surplus from trade between agents, an issue that desserves further investigation.
} 
$p_{\mathrm{i}}$ paid by $i$-agents who use the service, and taxes on transactions $t_{\mathrm{i}}$ charged on $i$-agents whenever they find their match through the cybermediary.

The monopolist cybermediary decides upon its pricing strategy $P=$ $\left(p_{1}, p_{2}, t_{1}, t_{2}\right)$, which is then observable by all agents on both sides of the market. Agents of both classes then decide simultaneously whether they register or not. It is obvious that the market allocation that emerges strongly depends upon the agents' beliefs about registration decisions by agents of the other population. Hence the possibility of multiple market allocation equilibria, which is not surprising with network externalities. ${ }^{5}$

The timing we consider, and that we extend straightforwardly in case of competition between intermediaries, deserves some comments. We attempt to capture the result of a fundamentally dynamic process by way of a static model, hence with some imperfection. The equilibria we characterize should be viewed as rational expectation equilibria with respect to users' decisions, following the choice of intermediation services prices in the first stage. Note that, due to the observability of prices, a modification of $p_{\mathrm{j}}$ may affect $i$-users' beliefs on the decisions of $j$-agents, and consequently impact both agents $i$ and $j$ decisions.

A market allocation describes how users of both populations decide and how many of them register with the cybermediary for given prices. In the monopolistic case, the market allocation for $j$-users is determined by their beliefs on $i$-users allocation $\tilde{n}_{\mathrm{i}}$ : $j$-users will register with the cybermediary only if $p_{\mathrm{j}} \leq \tilde{n}_{\mathrm{i}}\left(u_{\mathrm{j}}-t_{\mathrm{j}}\right)$. Moreover, in equilibrium, beliefs should be correct, $\tilde{n}_{\mathrm{i}}=n_{\mathrm{i}}$.

Network externalities may cause a coordination failure problem between the two populations of agents. For non-negative prices $P \geq 0$, there always exist market allocation with bad expectations from agents such that $n_{\mathrm{i}}(P)=$ 0 for all $i$ : there is no way to attract a population as agents are pessimistic about the other population not bothering to register for intermediation. For any reasonable prices (i.e. such that $u_{\mathrm{i}} \geq p_{\mathrm{i}}+t_{\mathrm{i}}$ ), there also always exists a market allocation with more optimistic beliefs where both types join $\left(n_{\mathrm{i}}(P)=\right.$ $1)$.

The maximum profit that a monopolist cybermediary can make on this market corresponds to the full appropriation of the matching surplus generated by intermediation, that is $\pi^{\mathrm{M}}=u_{1}+u_{2}$. With registration prices $p_{\mathrm{i}}=u_{\mathrm{i}}$ and no transaction taxes, the good-expectation market allocation yields maximum profits $\pi^{\mathrm{M}}$, while the bad-expectation market allocation yields zero profits. Transaction fees allows the monopolist to capture maximum profits while getting rid of the possibility of bad-expectation market

\footnotetext{
${ }^{5}$ See Farell-Saloner (1985), Katz-Shapiro (1985, 1994).
} 
equilibrium, as the monopolist can subsidize access and recover the subsidy on transaction taxes. In particular, it can propose $t_{\mathrm{i}}=u_{\mathrm{i}}$ and $p_{\mathrm{i}}$ negative but arbitrarily close to 0 . All agents then join because even if they expect no transaction to take place, they want to cash the subsidy. Thus it is now possible to secure the monopoly profit $\pi^{\mathrm{M}}$ even if coordination failure occurs.

\section{Competition and market dominance}

\subsection{Competition in access fees for exclusive services}

Let us now consider two competing cybermediaries, denoted $I$ and $E$. We shall be concerned initially with the analysis of imperfect competition between both cybermediaries when transaction are difficult to monitor and intermediation services are exclusive. The difficulty to monitor matches and transactions implies that the only feasible instruments are access or registration fees. The exclusivity assumption means that agents can only register with one intermediary and not with several: e.g. when posting a unique good to be sold off in auction-like websites, a seller cannot have several parallel selling procedures running at the same time for the same good, or at least he suffers a cost of doing so, in terms of reputation loss or future exclusion from the website where he defaults.

We focus on endogenously extreme asymmetric market structures that emerge in this setting, where one intermediary, $I$ as in "Incumbent", is a dominant firm: if it exists, such an equilibrium has only one active intermediary, i.e. $n_{\mathrm{i}}^{\mathrm{E}}=0$ for $i=1,2$, although both firms are ex ante symmetric and no fixed or entry costs exist. We are particularly interested in determining the maximum profits that are sustainable by the dominant firm in such an asymmetric equilibrium with de facto monopolization of the intermediation market. ${ }^{6}$

The game is one of simultaneous pricing, where both cybermediaries

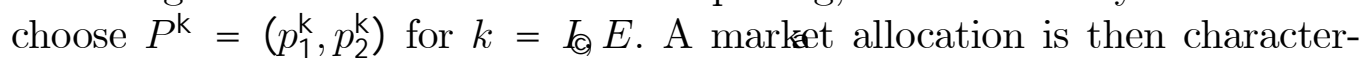
ized by the allocation of users $\underline{\underline{a}}_{i}^{\mathrm{k}}\left(P^{\mathrm{l}}, P^{\mathrm{E}}\right)_{\mathrm{i}, \mathrm{k}}$ such that given any $P^{\mathrm{I}}, P^{\mathrm{E}}$ and $n_{\mathrm{j}}^{\mathrm{k}}\left(P^{\mathrm{l}}, P^{\mathrm{E}}\right)_{\mathrm{k}}, n_{\mathrm{j}}^{\mathrm{k}}\left(P^{\mathrm{l}}, P^{\mathrm{E}}\right)_{\mathrm{k}}$ for $j \neq i$ is the result of a rational expectation market decision process by $j$-users. An equilibrium consists of pricing strategies and a system of market allocations for each possible price system, such that prices form an Nash equilibrium in the reduced-form pricing game induced by the system of market allocations.

\footnotetext{
${ }^{6} \mathrm{~A}$ complete analysis of asymmetric equilibria as well as other types of equilibria in provided is companion papers Jullien [2000] and Caillaud-Jullien [2000].
} 
The basic intuition is provided by a careful analysis of the best response of, say cybermediary $E$ to a set of prices $\left(p_{1}^{\prime}, p_{2}^{l}\right)$ set by cybermediary $I$. Fix $\left(p_{1}^{\prime}, p_{2}^{\prime}\right)$ and consider various pricing possibilities for $E$. Suppose that users of both populations hold favorable beliefs for intermediary $I$ so that $j$-users think that $n_{\mathrm{i}}=1$ whenever it is not irrational for $i$-users to do so (whenever it is not a dominated strategy for $i$-users to register with $I$ ); this makes it harder for intermediary $E$ to attract $j$-users and therefore to find a profitable pricing strategy. Cybermediary $E$ must charge prices so that there exist at least one class $i$ with $p_{\mathrm{i}}^{\mathrm{E}}$ satisfying:

$$
-p_{\mathrm{i}}^{\mathrm{E}}>u_{\mathrm{i}}-p_{\mathrm{i}}^{\mathrm{I}}
$$

in order to get some share of the market. Now, provided intermediary $E$ adopts a pricing strategy that finances defection of one side of the market $\left(p_{\mathrm{i}}^{\mathrm{E}}<p_{\mathrm{i}}^{\mathrm{l}}-u_{\mathrm{i}}\right)$, it is a dominant strategy for $i$-users to register to $E$ and $j$-users cannot rationally believe that $n_{\mathrm{i}}=1$. They hold (rational) beliefs that $n_{\mathrm{i}}^{\mathrm{E}}=1$ and must then consider registering to $E$ as well by comparing $u_{\mathrm{j}}-p_{\mathrm{j}}^{\mathrm{E}}$ with $-p_{\mathrm{j}}^{\mathrm{l}}$ and with 0 (if they do not register at all). So, with beliefs favorable to $I$, maximal profits for intermediary $E$ are given by:

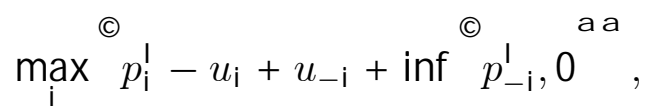

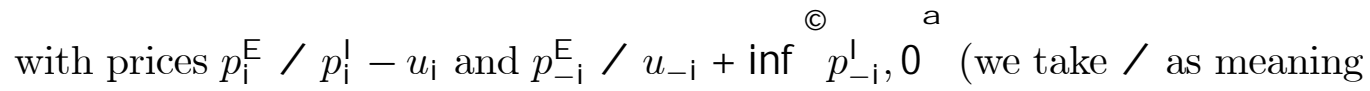
"slightly smaller than").

Then, it is easy to find the pricing strategy for cybermediary $I$ that guarantees that $E$ cannot capture any share of either market, or alternatively, in a sequential move game, that it cannot enter. It is sufficient to find prices so that the maximal profit for $E$ is non-positive.

Proposition 1 : There exists a dominant-firm market equilibrium where $I$ captures all trade and $E$ cannot attract any trade; it involves the following price system: $p_{1}^{\perp}=\inf \left\{-u_{1}, u_{1}-u_{2}\right\}<0, p_{2}^{1}=u_{2}$ and yields profits $\pi^{1}=$ inf $\left\{u_{1}, u_{2}-u_{1}\right\}>0$.

In equilibrium, both firms charge the above prices and, following a deviation from the equilibrium prices by one cybermediary, the agents coordinate on the allocation that is the most unfavorable to this deviating cybermediary. This pricing strategy is characterized by cross-subsidies: the low externality side of the market is subsidized by the high externality group, on which the dominant firm recoups the subsidy to group 1 and more by capturing the whole intermediation surplus $u_{2}$. Depending on the comparison between $u_{2}-u_{1}$ and $u_{1}$, the motive for the cross-subsidy varies. In 
the case $u_{2}-u_{1}>u_{1}, I$ subsidizes agents 1 to prevent $E$ from charging $p_{2}^{\mathrm{E}}=p_{1}^{\mathrm{I}}-u_{1}$ and $p_{2}^{\mathrm{E}}=u_{2}: E$ is indeed competing for type-2 agents and would "invest" in type- 1 as a way to attract group 2 . If $u_{2}-u_{1}>u_{1}$, prices are designed so as to prevent $E$ from charging $p_{2}^{\mathrm{E}}$ sightly negative and $p_{1}^{\mathrm{E}}$ sightly positive: here $E$ would subsidize group 2 in order to generate profit on type- 1 agents.

As is often the case with direct network externalities, our model with imperfect competition and indirect externalities therefore yields quite naturally strongly asymmetric market structures even though there are no fixed cost or cost of entry. Users' beliefs, which can be viewed as reputational capital or brandname image, plays the role of a powerful barrier to entry.

Finally, it is possible to show that reasonable symmetric equilibria involve zero profits (see Caillaud-Jullien [2000]), which strengthens the case for the study of dominant firm equilibria.

\subsection{Competition with transaction taxes}

In this sub-section, we maintain the assumption that intermediation services are exclusive so that registration can be made with one or the other intermediary, but not for both. We however introduce the possibility of monitoring transactions through the intermediary's website and so, for the cybermediaries, the possibility of using transaction taxes as another pricing instrument.

Let us again investigate $E$ 's best response prices to a system $\left(p_{\mathrm{i}}^{!}, t_{\mathrm{i}}^{!}\right)$for $i=1,2$, with favorable beliefs for intermediary $I$. To attract one population $i$ of users, $E$ must subsidize this population, which can only be done by paying access bonuses since $i$ expects no transaction to take place through $E$. Hence, $p_{\mathrm{i}}^{\mathrm{E}}$ must be (slightly) below $t_{\mathrm{i}}^{\mathrm{I}}+p_{\mathrm{i}}^{\mathrm{I}}-u_{\mathrm{i}}$. With this subsidy, it is a dominant strategy for $i$-users to register to $E$, irrespective of $t_{\mathrm{i}}^{\mathrm{E}}$. So, it is possible to charge $t_{\mathrm{i}}^{\mathrm{E}}=u_{\mathrm{i}}$ without jeopardizing the shift from $I$ to $E$ by $i$-users, and this clearly reduces by an amount $u_{\mathrm{i}}$ the cost for $E$ of attracting group $i$. Given that $i$-users now unambiguously register with $E$, beliefs have to be that $n_{\mathrm{i}}^{\mathrm{E}}=1$. So, $j$-users have to compare $u_{\mathrm{j}}-t_{\mathrm{j}}^{\mathrm{E}}-p_{\mathrm{j}}^{\mathrm{E}}$ with $-p_{\mathrm{j}}^{\mathrm{l}}$ and 0 and they will decide to register with $E$ provided:

$$
t_{\mathrm{j}}^{\mathrm{E}}+p_{\mathrm{j}}^{\mathrm{E}} \leq u_{\mathrm{j}}+\min \stackrel{\mathrm{C}^{\mathrm{l}}}{p_{\mathrm{j}}, 0^{\underline{a}}} \text {. }
$$

The maximal profits for $E$ are then:

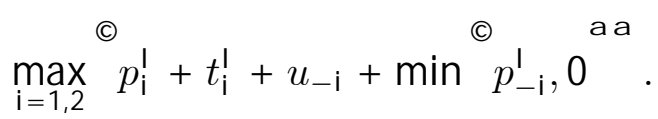

A dominant firm structure requires from the dominant firm a pricing strategy such that the above maximal profits are null, that users agree to 
register with $I$ (i.e. $u_{\mathrm{i}} \geq p_{\mathrm{i}}^{\prime}+t_{\mathrm{i}}^{!}$) and, though, that the dominant firm profits are non-negative: $p_{1}^{1}+t_{1}^{1}+p_{2}^{1}+t_{2}^{1} \geq 0$. It follows that the dominant firm has in fact no market power at all:

Proposition 2: When cybermediaries compete for exclusive services with access fees and transaction fees, dominant-firm equilibria exist but imply zero profits.

Putting $E$ out of the market requires that at least for one $i, p_{\mathrm{i}} \leq-u_{1}-u_{2}$. The maximum profit equilibrium with $I$-dominance is obtained with: $p_{1}^{\mathrm{k}}=$ $-u_{1}-u_{2}, t_{1}^{\mathrm{k}}=u_{1}, p_{2}^{\mathrm{k}}=0$ and $t_{2}^{\mathrm{k}}=u_{2}$ (or symmetrically, changing indices). The externality generated on one side of the market is taxed away by the dominant firm $\left(p_{2}^{l}+t_{2}^{1}=u_{2}\right)$ so as to subsidize the other side of the market by the same amount $\left(p_{1}^{1}+t_{1}^{1}=-u_{2}\right)$, so that one side of the market is subsidized entirely by the surplus of the other side. The aim of the strategy is to create a strong bond with one population, financed through the capture of all surplus from the other side of the market. Potential competition is thus extremely effective in keeping intermediaries' profits to the minimum and avoiding market power due to biased beliefs of users, although it generates market dominance and a strong pattern of cross-subsidization.

The possibility of using more sophisticated pricing instruments has thus strong consequences on the result of imperfect competition in intermediation. It reduces profits: dominant firm equilibria are now extremely costly for the dominant firm that is unable to draw positive profits from its market dominance. This conclusion also applies for other types of equilibria, in particular for symmetric equilibria (see Caillaud-Jullien [2000]).

\subsection{Competing cybermediaries and multi-homing}

We now relax our exclusivity assumption and we investigate the possibility for users to register not only with one cybermediary but also with both of them. This accounts for standard practice of firms posting adds or referencing products and services on several intermediaries' website, or of users relying on several search engines to get a satisfactory answer to their query.

The game is the following. Cybermediaries set prices simultaneously and publicly; then, all users decide simultaneously on their intermediation service provider(s). We will proceed as in the sub-section 4.1 by restricting attention to pricing strategies that only consist in access fees and by analyzing the best response from $E$ to a price system $\left(p_{1}^{\prime}, p_{2}^{\prime}\right)$ with meaningful prices, that is with $p_{\mathrm{i}}^{\mathrm{k}} \leq u_{\mathrm{i}}$.

First, and very much in the same vein as previously, it is immediate that with beliefs favorable to $I$, there is no way for intermediary $E$ to capture 
some share of the market if $p_{1}^{\mathrm{E}}>0$ and $p_{2}^{\mathrm{E}}>0$. Again, intermediary $E$ has to subsidize one side of the market. But now, any negative price $p_{\mathrm{i}}^{\mathrm{E}}<0$ can attract $i$-users to $E$ as an additional intermediary, even if they think that $n_{\mathrm{j}}=1$ : registering with $E$ then simply allows users to cash the subsidy without having to forego the positive externality from the other intermediary. So, attracting one side of the market is less costly for $E$ than with exclusive services. It is sufficient to grant free access to $i$-users (actually, to charge an infinitely small negative price). ${ }^{7}$

On the other hand, it makes sense to subsidize one side of the market only if this strategy generates a bandwagon effect and attracts, through the presence of positive externalities, the other side of the market on which the intermediary can recoup its losses. With non-exclusive services, it can be that $n_{\mathrm{i}}^{\mathrm{E}}=1$ while $n_{\mathrm{i}}$ is still equal to 1 ; attracting $i$-users does not necessarily mean that they have to quit the other cybermediary. In this case, there is not necessarily a reason for $j$-users to switch to intermediary $E$. To attract the other side of the market, $E$ must charge $p_{\mathrm{i}}^{\mathrm{E}} / \quad 0$ and $p_{\mathrm{j}}^{\mathrm{E}}$ such that:

$$
u_{\mathrm{j}}-p_{\mathrm{j}}^{\mathrm{E}}{ }^{\prime} u_{\mathrm{j}}-p_{\mathrm{j}}^{\mathrm{I}}
$$

that is $p_{\mathrm{j}}^{\mathrm{E}} / p_{\mathrm{j}}^{\mathrm{l}}$. Hence, attracting the other, profitable side of the market generates smaller profits with non-exclusive services as the externality surplus cannot be entirely captured.

It is then easy to derive the best profit that $E$ can generate by the choice of an apropriate price system, when beliefs are favorable to $I$ : it is equal to $\max 0 ; p_{1}^{\mathrm{I}} ; p_{2}^{\mathrm{I}}$; each case is obtained respectively for prices $\left(p_{1}^{\mathrm{E}}, p_{2}^{\mathrm{E}}\right)$ equal $(0,0),\left(p_{1}^{\prime}, 0\right)$ and $\left(0, p_{2}^{\prime}\right)$. From this characterization, it is immediate that a dominant firm equilibrium must necessarily entail $p_{\mathrm{i}}^{!}=0$ for $i=1,2$. Otherwise, there would exist a profitable entry strategy for the inactive firm. Indeed, as in sub-section 4.2, there exists a dominant firm equilibrium, but it is a knife-edge case. All prices are null and, although they are indifferent between all options, users from both sides just choose to register with the cybermediary with the higher reputation. This reputation should be modelled as the result of some historical, dynamic process and here, it is important that all users share the same perception of reputation. So, cybermediary $I$ can be dominant and monopolize the intermediation market, but this does not generate monopoly profits.

\footnotetext{
${ }^{7}$ In the case of multi-homing, there may be additional costs compared to exclusivity. Indeed the agent must be induced not only to register but also to use the service or at least to provide the adequate information for $\mathrm{E}$ to perform a match. If there is some usage cost beared by users, they may decide to register but to use only to the other service. One solution is to propose the subsidy under the form of a free service that is only valuable when used combined with active participation.
} 
Proposition 3 : With multi-homing and no transaction fees, there exist dominant firm equilibria; the dominant firm makes zero profits (and of course the inactive firm as well) and it grants free access on both sides of the market.

Winning a dominant position is therefore not so attractive for an intermediary when competition develops on non-exclusive services, and potential competitive pricing strategies force the dominant firm to zero profits.

It is worth mentioning here additional results obtained in Caillaud-Jullien [2000]. They show that symmetric equilibria imply zero profits as well, except for one class of equilibrium with one-sided multihoming. As an example, the following price system: $p_{1}^{\mathrm{k}}=0, p_{2}^{\mathrm{k}}=\frac{\mathrm{u}_{2}}{2}$ can be sustained as an equilibrium. The market allocation is such that users of group 1 (who get free access) split between both cybermediaries, while users of type 2 follow a multihoming strategy and register with both cybermediaries. ${ }^{8}$ This symmetric equilibrium is characterized by peaceful market sharing, where both cybermediaries agree to grant free access to one group of users and coordinate pricing on the other group so as to capture and share their entire surplus. Cybermediation profits are positive in such a configuration.

\section{Discussion and further developments}

Compared with the benchmark case of competition with exclusivity and simple access fees, our paper suggests that the availability of more sophisticated pricing instruments, such as transaction taxes, and the possibility of pursuing multi-homing strategies, that is several registrations with several intermediaries, may deeply affect the market structure that emerges on the intermediation market. Aggressive strategies aiming at keeping the opponent out of the market and monopolization may be less of an issue, intermediation profits may be more limited.

This paper obviously misses some important features of intermediation activities on the world wide web. In companion papers (Jullien [2000], CaillaudJullien [2000]), we propose a more complete analysis of equilibrium configurations and we take into account connection and configuration costs. Jullien [2000] also investigates some aspect of differentiation (horizontal or vertical) among intermediation websites. Differentiation may be the result of targeted audience (B2B vs B2C), or the result of the choice of services provided in addition to basic intermediation (historic user's profile, certification,...). Advertising is a major source of income for large intermediation websites

\footnotetext{
${ }^{8}$ Out of the equilibrium path, users follow a market allocation rule that is most favorable to the non-deviating cybermediary.
} 
such as Yahoo! ...Because advertising resources (and even more sponsoring) are directly related to the size of the audience, competition with advertising resources will result in even lower prices than in our model (see GaudeulJullien (2000)). Other aspects would be worth investigating such as a more realistic model of sequential search, the possibility of cybermediaries to play a role in transaction price formation (see Diamond (1984a)), the monitoring and screening role of intermediaries (Rubinstein-Wolinski (1987), Diamond $(1984 b))$ and the impact of intermediation pricing on trade inefficiencies (and not only on agents' participation).

\section{R eferences}

[1] Caillaud, B. and B.Jullien, (2000): "Competition between match-makers on the Internet", work in progress

[2] Diamond P. (1984a): A search Equilibrium A pproach to the Micro Foundations of Macroeconomics, MIT Press, Cambridge.

[3] Diamond P. (1984b): "Financial Intermediation and Delegated Monitoring", Review of E conomic Studies 51, 393-414.

[4] Farrell, J. and G. Saloner (1985): "Standardization, Compatibility and Innovation", Rand J ournal of Economics 16, 70-83.

[5] Gaudeul A. et B. Jullien (2000): "Commerce électronique: vers une analyse économique", mimeo

[6] Innes R. and R. Sexton (1993): "Customer Coalitions, Monopoly Price Discrimination, and Generic Entry Deterrence", European E conomic Review 37, 1569-1597.

[7] Jullien B. (2000): "Chicken and Egg: Cross-Subsidization by Competing Networks ", Mimeo IDEI

[8] Kaplan S. and M Sawhney (2000): "B2B E-Commerce Hubs: Towards a Taxonomy of Business Models", Harvard Business Review (forthcoming, May-June 2000).

[9] Katz, M. and K.Shapiro (1985): "Network Externalities, Competition and Compatibility", A merican Economic Review 75, 424-440.

[10] Katz, M. and K. Shapiro (1994): "System Competition and Network Effects", J ournal of E conomic Perspective 8, 93-115. 
[11] "Measuring the Internet Economy", University of Texas at Austin, Center for Research in Electronic Commerce, 6 juin 2000, http://www.internetindicators.com.

[12] Rubinstein-Wolinsky (1987): "Middelmen", Quaterly J ournal of E conomics 102, 581-593.

[13] The Economist: "Shopping Around the World", E-commerce survey, 26th February 2000.

[14] Varian H. and K. Shapiro (1998): Information Rules, Havard Business School Press.

[15] Yanelle M.O. (1996): "Can Intermediaries Replace the Walrasian Auctioneer", DELTA working paper. 